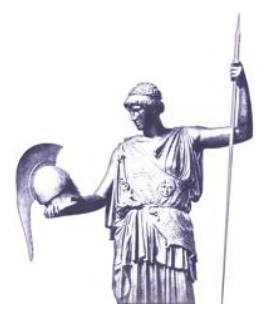

Connections: The Quarterly Journal

ISSN 1812-1101, e-ISSN 1812-2973

Надя Миланова, Connections QJ 19, № 3 (2020): 78-88

https://doi.org/10.11610/Connections.rus.19.3.05

Рецензированная статья

\title{
Институциональная устойчивость и повышение добропорядочности в секторе обороны и безопасности
}

\section{Надя Миланова}

Международный секретариат HATO, https://www.nato.int/

\begin{abstract}
Резюме: Концепция устойчивости в сфере обороны и безопасности развивается в сторону включения широкого и многомерного набора уязвимостей и связанных с ними стратегий смягчения по всему спектру военных и невоенных механизмов реагирования. В этой статье утверждается, что, хотя коррупция и неэффективное управление в настоящее время признаны угрозой безопасности, как это сформулировано в Декларации Варшавского саммита НАТО, укрепление оборонных и связанных с ними институтов безопасности как в странах-союзниках, так и в странах-партнерах все еще требует дальнейшего включения в качестве неотъемлемой части концепцию устойчивости. Институциональная устойчивость, основанная на честности, прозрачности и подотчетности, имеет решающее значение для обеспечения выполнения обязательств НАТО по устойчивости и ее базовых требований, которые включают, inter alia [в частности], преемственность управления с его способностью принимать решения и предоставлять общественные услуги населению. Коррупция и неэффективное управление подрывают доверие общества и усугубляют нестабильность и хрупкость. Политика НАТО по обеспечению добропорядочности способствует выполнению трех основных задач Североатлантического союза - коллективной обороны, кризисного менеджмента и безопасности, основанной на сотрудничестве. Работа НАТО по Проецированию стабильности по отношению к партнерам показала значение роли хорошего управления как компонента повышения устойчивости партнеров. Это требует дальнейшей институционализации посредством последовательных усилий по укреплению оборонных институтов. Вклад институциональной устойчивости в задачи НАТО по обороне и сдерживанию требует дальнейшего осмысления. В статье приводятся аргументы в пользу более последовательного подхода к использованию
\end{abstract}


программы Повышение добропорядочности (Building Integrity) как неотъемлемой части концепции устойчивости и необходимости в надежных институциональных способностях для снижения уязвимости, возникающей из-за риска коррупции, как угрозы безопасности.

Ключевые слова: НАТО, сектор обороны и безопасности, институциональная устойчивость, повышение добропорядочности, ПД, прозрачность, подотчетность, коррупция, хорошее управление.

\section{Введение}

Устойчивость - одна из тех новых концепций, которые демонстрируют экспоненциальный рост использования в широком спектре областей и международных организаций. Повсеместное распространение этой концепции одновременно обнадеживает, поскольку она фокусируется на причинном эффекте множества факторов и их взаимосвязях, но также подвержена опасности чрезмерного - и, следовательно - неправильного использования без разработки прочной основы и концептуальной рамки. В этом отношении будет ли потенциал концепции устойчивости использоваться международными организациями как верный указатель для практических решений сложных проблем, или он будет использоваться как "фиговый листок», когда невозможно примирить недостаточно амбициозные и чрезмерно амбициозные крайности их повесток выработки политики?

Обзор использования устойчивости в международных организациях, как части их повестки дня и выработки политики, показывает следующие тенденции. В дискурсе $\mathrm{OOH}$ концепция устойчивости была введена в контексте устойчивого развития, при этом устойчивость социальных и экологических систем используется в качестве меры для достижения Целей устойчивого развития (ЦУР). Подход Организации Объединенных Наций (ООН) к устойчивости направлен в первую очередь на снижение риска и менеджмент реакции на стихийные бедствия и стремится предоставить аналитическую основу показателей для измерения устойчивости в этом контексте.

Со своей стороны, Организация экономического сотрудничества и развития (ОЭСР) подчеркивает необходимость сотрудничества между сообществами, работающими над различными политиками, связанными с рисками в рамках стратегий развития. Определение устойчивости ОЭСР делает упор на «способность домохозяйств, сообществ и наций преодолевать потрясения и восстанавливаться после них, а также позитивно адаптировать и трансформировать свои структуры и средства для жизни перед лицом долговременных стрессов, изменений и неопределенности ". ${ }^{1}$ Внедряя системный анализ устойчивости, ОЭСР выступает за более эффективное, межот-

1 OECD, "Guidelines for Resilience Systems Analysis: How to Analyse Risk and Build a Roadmap to Resilience" (OECD Publishing, 2014), www.oecd.org/dac/Resilience\%20 Systems\%20Analysis\%20FINAL.pdf. 
раслевое и многомерное программирование посредством изучения взаимосвязей различных рисков и уязвимостей. Со своей стороны, программа обеспечения устойчивости Всемирного банка охватывает такие области, как управление рисками бедствий, изменение климата и инфраструктура, оказывающие влияние на результаты развития.

В своей Глобальной стратегии 2016 года Европейский Союз принял экспансионный подход к устойчивости, сделав ее неотъемлемой частью своей внешнеполитической роли и целей и одним из пяти приоритетов своей внешней деятельности наряду с другими четырьмя приоритетами, а именно: безопасность ЕС, комплексный подход к конфликтам, региональные порядки, основанные на сотрудничестве и глобальное управление. ${ }^{2}$ В этом смысле подход к устойчивости в контексте Глобальной стратегии 2016 года является отходом от более раннего использования этой концепции Европейским союзом, который уделял основное внимание развитию и гуманитарным вопросам, как это сформулировано в «Европейском подходе к устойчивости: уроки продовольственной безопасности и ее кризисов» (2012), Заключении Совета о подходе ЕС к устойчивости (2013) и Плане действий по обеспечению устойчивости в странах, подверженных кризисам (2013). Говоря языком ЕС, устойчивость к внешним воздействиям распространяется на государство и общества, где «жизнеспособное общество с демократией, доверием к институтам и устойчивым развитием лежит в основе устойчивого государства», а сама устойчивость определяется как «способность государств и обществ реформироваться, и таким образом, противостоять внутренним и внешним кризисам и восстанавливаться после них». ${ }^{3} \mathrm{~B}$ этом отношении более широкая и многогранная концепция устойчивости, разработанная и используемая Европейским союзом, предполагает широкий спектр путей во множестве областей, таких как содействие «устойчивости демократий», усиление «устойчивости к внешним воздействиям критически важной инфраструктуры, сетей и услуг», а также «создание устойчивости общества, в том числе путем углубления работы в области образования, культуры и с молодежью, чтобы способствовать плюрализму, сосуществованию и уважению». ${ }^{4}$ В геополитическом плане устойчивость является стратегическим приоритетом для Европейского Союза в политике соседства на востоке и юге, а также подтверждается взаимосвязь между внутренними и внешними измерениями ее операционализации.

2 "Shared Vision, Common Action: A Stronger Europe. A Global Strategy for the European Union's Foreign and Security Policy," June 2016, https://eeas.europa.eu/ar chives/docs/top_stories/pdf/eugs_review_web.pdf.

3 "Shared Vision, Common Action."

4 "Shared Vision, Common Action." 


\section{Подход НАТО к устойчивости}

Точно так же, как и в области устойчивого развития, концепция устойчивости в сфере обороны и безопасности также развивается в сторону включения широкого и многомерного набора уязвимостей и связанных с ними стратегий смягчения последствий по всему спектру военных и невоенных механизмов реагирования. В этой связи повестка дня НАТО по обеспечению устойчивости имеет тенденцию расширяться и брать на себя новые задачи по мере того, как со временем развивается понимание факторов риска и возможных контрстратегий.

Идея устойчивости государств-членов НАТО посредством поддержания и развития их индивидуальной и коллективной обороноспособности закреплена в учредительном договоре Альянса от 1949 года и, в частности, в статье 3. Это определенное в неявном виде внутреннее измерение устойчивости с точки зрения способностей и потенциала коллективной обороны вводится в действие в рамках процесса оборонного планирования и развития НАТО. Лондонская декларация, принятая на встрече лидеров НАТО 3-4 декабря 2019 г., расширяет концептуальные рамки устойчивости, впервые включая в нее общества стран НАТО, а также устойчивость критически важной инфраструктуры и энергетическую безопасность, как и надежные и отказоустойчивые системы для обеспечения коммуникационной безопасности стран НАТО. Помимо устойчивости общества, четко сформулированной впервые, другие области уже были частью повестки дня НАТО по обеспечению устойчивости.

Основа повестки дня НАТО по обеспечению устойчивости лежит в области гражданской готовности, которая возникает как необходимость в быстро меняющихся условиях безопасности и в результате усиления обороноспособности и способности к сдерживанию Североатлантического союза с учетом возрастающих террористических и гибридных угроз, нацеленных на гражданское население и критическую инфраструктуру на евроатлантической территории. На Варшавском саммите в 2016 году лидеры Североатлантического союза решили повысить устойчивость НАТО так, чтобы она охватывала полный спектр угроз и согласовала семь базовых требований к национальной устойчивости, на основании которых государства-члены могут измерять уровень своей готовности. ${ }^{5}$ К ним относятся гарантированная непрерывность государственного управления и важнейших государственных услуг; надежные источники энергии; способность эффективно справляться с неконтролируемым перемещением людей, устойчивые продовольственные и водные ресурсы; способность справляться с ситуациями с большим числом погибших; устойчивые системы гражданской связи и устойчивые системы гражданского транспорта.

5 NATO official text, "Commitment to Enhance Resilience Issued by the Heads of State and Government Participating in the Meeting of the North Atlantic Council in Warsaw, 8-9 July 2016," https://www.nato.int/cps/en/natohq/official_texts_133180.htm. 
Кризис COVID-19 стал проверкой готовности Североатлантического союза и его государств-членов проявлять устойчивость, в том числе в секторе здравоохранения, который до этого явно не определялся в качестве отдельной области требований, например, с точки зрения медицинских запасов и готовности к пандемиям. Пандемия проверила действующие механизмы НАТО для консультаций и координации во время чрезвычайной ситуации, а также скорость реагирования для смягчения последствий кризиса в области здравоохранения как в странах НАТО, так и в странах-партнерах за счет способностей для быстрого реагирования реализованные в Евроатлантическом центре координации реагирования на чрезвычайные ситуации (EARDCC) в качестве основного механизма реагирования НАТО на гражданские чрезвычайные ситуации. Кризис COVID-19 также выявил другие аспекты устойчивости, которые необходимо учитывать, такие как реагирование на дезинформацию в кризисных ситуациях и формирование способности быстро оправиться от негативного социального и политического воздействия распространения ложных новостей в условиях кризиса. Параллельно ответные меры на пандемию выдвинули проблемы, связанные с устойчивостью и надежностью цепочек поставок в быстро меняющейся среде, которая требует быстрого реагирования, в результате чего ожидается, что надзор и контроль будут ограничены и сведены к минимуму, что приведет к увеличению риску мошенничества и нецелевого использования ресурсов. Таким образом, в то время, как для НАТО повестка дня по обеспечению устойчивости прочно закреплена в контексте основной задачи Североатлантического союза по коллективной обороне и его последующей позиции по обороне и сдерживанию, а также по гражданской готовности, список рисков и уязвимостей, для которых необходимо разработать меры по обеспечению устойчивости и ввести заранее, неизбежно будут расти.

\section{Повестка дня по обеспечению устойчивости: прогнозирование рисков и уязвимостей}

B целом, COVID-кризис продемонстрировал непредсказуемость и сложность повестки дня по обеспечению устойчивости и стал испытанием для мышления международных организаций и национальных правительств в отношении устойчивости. В Отчете о глобальных рисках за 2020 год Всемирного экономического форума, опубликованном в январе 2020 года, пандемии или инфекционные заболевания не входят в первую десятку рисков с точки зрения их вероятности возникновения. ${ }^{6}$ В 2020 году риски с наибольшей ожидаемой вероятностью возникновения будут преимущественно экологического характера, за которыми следуют два технологических риска (мошенничество с данными, кража данных и кибератаки), один социальный (водный кризис), один геополитический (провал глобального управления) и

6 World Economic Forum, The Global Risks Report 2020, Insight Report, $15^{\text {th }}$ edition, https://www.weforum.org/reports/the-global-risks-report-2020. 
один экономический (пузырь активов). Что касается воздействия, первые два риска с наивысшей оценкой - это провал действий по борьбе с изменением климата и оружие массового уничтожения, причем последнее является единственным риском геополитического характера в этом списке, а воздействие инфекционных заболеваний находится на десятом месте. По сравнению с предыдущими годами пандемия воспринималась как риск в 2007 г. на четвертом месте рейтинга и в 2008 г. на пятом месте, что совпадает со вспышкой инфекции вирусом H5N1. Однако в последующие годы восприятие риска пандемии снизилось, и он так и не попал в первую десятку рисков с наибольшей вероятностью возникновения и, конечно же, не в период, предшествующий кризису COVID-19.

Следовательно, мышление устойчивости не может существовать в отрыве от способности международных организаций и национальных правительств прогнозировать и заранее определять какие из множества рисков и уязвимостей будут представлять угрозу безопасности в тот или иной момент и, соответственно, готовить механизмы преодоления последствий, стратегий менеджмента и смягчения последствий. Понимание всего диапазона потенциальных рисков безопасности в их сложности, независимо от представлений об их вероятности возникновения, является непременным условием разработки адекватных и конкретных решений, для реализации некоторых из которых могут потребоваться годы и встраивания в организационные системы, чтобы обеспечить эффективный ответ в случае необходимости.

\section{Коррупция как риск для безопасности: расширение повестки дня по устойчивости}

Если мы определяем устойчивость, в первую очередь, как способность предвидеть появление уязвимостей, независимо от их низкой или высокой вероятности возникновения, первым шагом в процессе демистификации и развязывания концепции устойчивости в ее многогранной природе должен стать анализ всего диапазона потенциальных рисков и их способности создавать проблемы безопасности. В этом отношении коррупция и плохое управление, хотя и определены как риски для безопасности, не занимают особо важное место в повестке дня по обеспечению устойчивости. Это может быть объяснено преобладающим представлением о низком воздействии, вызываемом ими, по сравнению с сильным воздействием, связанным с другими рисками безопасности, такими как распространение оружия массового поражения или нарушение работы критически важной инфраструктуры. 
В анализе глобальных рисков Всемирного экономического форума коррупция попадает в группу геополитических рисков. ${ }^{7}$ Только в годовом докладе за 2011 год она был идентифицирована как риск с высокой вероятностью на высоком третьем месте. Высокий рейтинг коррупции как глобального риска в 2011 году может объяснить публикация Большой базы данных о коррупции Всемирного банка в 2012 году, в которой собрана коллекция случаев за период с 1980 по 2011 год, а также накопление громких дел о коррупции государственных должностных лиц и частных компаний в преддверии 2011 года. В годовом отчете за 2020 год коррупция рассматривается как один из факторов, способствующих провалу государственного управления, определяя его как «неспособность управлять страной, имеющей геополитическое значение в результате слабого верховенства закона, коррупции или политического безвыходного положения». ${ }^{8}$ Связь между коррупцией и несостоятельностью государственного управления существенна и усиливает вызовы управления и устойчивости, создаваемые коррупцией как угрозой безопасности. В 2020 году неэффективность государственного управления оценивалась выше с точки зрения вероятности и воздействия по сравнению с риском террористических атак.

Для НАТО работа над коррупцией как угрозой безопасности и над минимизацией риска ее возникновения в оборонном секторе и связанном с ним секторе безопасности началась в 2007 году, когда была учреждена Программа повышения добропорядочности НАТО (НАТО ПД). Это является практическим решением для реализации Плана действий партнерства НАТО по строительству оборонных институтов (PAP-DIB), одобренного на саммите НАТО в Стамбуле в 2004 году, с его десятью принципами, которые считаются основополагающими для строительства эффективных и демократически ответственных оборонных институтов, а именно демократический контроль над оборонной деятельностью; гражданское участие в разработке политики обороны и безопасности; эффективный и прозрачный законодательный и судебный надзор за сектором обороны; эффективные и прозрачные механизмы и процедуры для оценки рисков безопасности и требований национальной обороны; эффективные и прозрачные меры по оптимизации управления министерствами и ведомствами, отвечающими за вопросы обороны и соответствующими силовыми структурами, включая процедуры для облегчения межведомственного сотрудничества; эффективные и прозрачные механизмы и методы, обеспечивающие соблюдение международно признанных норм и практик, установленных в оборонном секторе, включая экспортный контроль оборонных технологий и военной техники; эффективные и прозрачные кадровые структуры и практики в силах обороны; эффективные и прозрачные процедуры финансирования, планирования и распределения ресурсов в сфере обороны; эффективное, прозрачное

7 World Economic Forum, The Global Risks Report 2020.

8 World Economic Forum, The Global Risks Report 2020, 87. 
и экономически выгодное управление расходами на оборону; и эффективные и прозрачные механизмы для обеспечения эффективного международного сотрудничества и добрососедских отношений в вопросах обороны и безопасности. ${ }^{9}$

По своей сути, эти принципы представляют собой требования и строительные блоки устойчивости в интегрированном виде - по горизонтали во всех функциональных областях, присущих оперативному функционированию оборонных институтов, а также по вертикали в рамках общегосударственной структуры. Эффективные и действенные оборонные институты также являются в более широком смысле устойчивыми институтами, которые имеют в своем распоряжении правильные механизмы для поддержания целостности системы в первую очередь и, таким образом, предотвращения возникновения негативных явлений. У них также есть механизмы преодоления последствий потрясений для системы в случае их возникновения.

НАТО зафиксировало взаимосвязь между коррупцией и безопасностью в своей Политике повышения добропорядочности (ПД), одобренной главами государств и правительств стран НАТО на саммите в Варшаве в 2016 году. ${ }^{10}$ Сама Политика ПД и Коммюнике Варшавского саммита четко сформулировали, что «коррупция и неэффективное управление -это вызовы безопасности, которые подрывают демократию, верховенство закона и экономическое развитие», и что «прозрачные и подотчетные оборонные институты под демократическим контролем имеют фундаментальное значение для стабильности в евроатлантическом регионе и важное значение для сотрудничества в области международной безопасности». ${ }^{11}$

На саммите НАТО в Брюсселе в 2018 году создание более сильных оборонных институтов партнеров НАТО, улучшение их надлежащего управления и повышение их устойчивости по их просьбе было определено как отдельное направление работы в контексте усилий Североатлантического союза по проецированию стабильности как части его широкой и усиливающейся позиции сдерживания и обороны. ${ }^{12}$ Это ближе всего к тому, чтобы вопрос эффективного управления и сильных оборонных институтов был поставлен в центр повестки дня Североатлантического союза по обеспечению

9 NATO, "Partnership Action Plan on Defence Institution Building (PAP-DIB)," January 7, 2004, https://www.nato.int/cps/en/natohq/official_texts_21014.htm.

10 NATO, "NATO Building Integrity Policy, Endorsed by the Heads of State and Government participating in the meeting of the North Atlantic Council in Warsaw 8-9 July 2016," July 9, 2016, https://www.nato.int/cps/en/natohq/official_texts_135626.htm.

11 NATO, "Warsaw Summit Communiqué, Issued by the Heads of State and Government participating in the meeting of the North Atlantic Council in Warsaw 8-9 July 2016," July 9, 2016, para. 130, www.nato.int/cps/en/natohq/official_texts_133169.htm.

12 NATO, "Brussels Summit Declaration, Issued by the Heads of State and Government participating in the meeting of the North Atlantic Council in Brussels 11-12 July 2018," July 11, 2018, para. 50, www.nato.int/cps/en/natohq/official_texts_156624.htm. 
устойчивости. В то время как НАТО де-факто работает над повышением устойчивости оборонных и связанных с ними институтов безопасности, эта связь все еще нуждается в более сильном обосновании, а важность сильных институтов как источника и гаранта устойчивости требует более узнаваемой формулировки. Более того, Политика ПД применяется как к союзникам, так и к партнерам, а также к НАТО как к организации, и способствует выполнению трех основных задач Североатлантического союза: коллективной обороны, кризисного менеджмента и безопасности, основанной на сотрудничестве.

Хотя это и не сформулировано явно, акцент Политики ПД на хорошем управлении также согласуется с базовыми требованиями НАТО к устойчивости и, в частности, с первым требованием, которое связано с непрерывностью управления, его способностью принимать решения и предоставлять услуги населению. Это согласование между определением коррупции как угрозы безопасности в НАТО и программой обеспечения устойчивости концептуально основано на причинно-следственной связи между национальным управлением и принципами добросовестности, прозрачности и подотчетности, как в качестве механизма устойчивости, который сам по себе защищает от вероятности злоупотреблений и должностных преступлений, с одной стороны, так и в качестве показателя устойчивости на институциональном уровне, с другой.

\section{Замыкание цикла: институциональная устойчивость и повыше- ние добропорядочности}

Концепции устойчивости и добропорядочности имеют некоторые общие характеристики, в частности позитивные подходы, которые они вводят в отношении сложных явлений с негативным влиянием в контексте безопасности и развития, таких как хрупкость, уязвимость, коррупция и плохое управление. Точно так же, пути к усилению устойчивости и повышению добропорядочности проходят через преобразующие изменения и нормативную адаптацию, требующие вмешательства с целью изменения политики и институциональных реформ на уровне организационной культуры, мышления и способностей, а также индивидуальных умений, взглядов и поведений. Устойчивость возлагает бремя усилий на принимающую сторону интервенции международной организации также, как и в случае концепции добропорядочности, которая предполагает внутреннюю силу и внутренний потенциал.

Союзники и партнеры по НАТО согласовали определение добросовестности при обсуждении Политики ПД, указав на добропорядочность как на связь между поведением и принципами. Кроме того, согласно определению НАТО, с институциональной точки зрения добросовестность напрямую связана с надлежащим управлением. Политика ПД подтверждает, что «укрепление добропорядочности института - это вопрос институционализа- 
ции принципов, которые мы хотим, чтобы институт отстаивал, а также вопрос обобществления этих норм и ценностей среди его персонала». ${ }^{13}$ Таким образом, добропорядочность существует на двух уровнях-институциональном и индивидуальном. Два уровня постоянно взаимодействуют и подкрепляют друг друга посредством динамического процесса. Благодаря системному подходу, ПД НАТО сосредоточена на выявлении и оценке пробелов и уязвимостей с точки зрения минимизации риска коррупции с помощью диагностического инструмента, известного как Процесс самооценки и коллегиального контроля ПД НАТО. На основе анализа национальных потребностей и требований добросовестности ПД НАТО предоставляет индивидуальную поддержку и индивидуальные решения, тем самым способствуя устойчивости оборонных институтов к злоупотреблениям, должностным преступлениям и мошенничеству в различных функциональных областях, таких как управление человеческими ресурсами, финансовые ресурсы, управление, бюджетирование и планирование, закупки, управление жизненным циклом, цепочки поставок, логистика, списывание активов и т.д. ${ }^{14}$

В этом смысле институциональная устойчивость основана на совокупности системных факторов и на совокупности механизмов, способных сдерживать риски для системы в различных институциональных функциональных областях, которые взаимодействуют и взаимно усиливают или подрывают друг друга. Например, прозрачная и подотчетная система найма и продвижения по службе, основанная на заслугах, усилит систему закупок, управления активами или любую другую функциональную область за счет применения принципа «нужный человек в нужном месте». В этом отношении риски, относящиеся к соответствующим областям, а также риски в каждой области должны быть детализированы, оценены и проанализированы в соответствии с их вероятностью возникновения и воздействия, если они возникнут, и, следовательно, приведут разработке новой политики и процедур. Этот процесс также включает в себя организационный этос, сумму ценностей и поведений, а также пути их социализации в рамках организации.

\section{Заключение}

Устойчивость стала для международных организаций объединяющей концепцией, позволяющей связывать различные политические сообщества и разрушать секторальные разрозненности. Будучи неконфликтной и бесспорной, концепция устойчивости привлекательна для разработчиков и исполнителей политики в качестве отправной точки при разработке политики и программных мероприятий в различных контекстах в различных дисци-

13 NATO, "NATO Building Integrity Policy."

14 Процесс ПД НАТО включает в себя процесс самооценки и коллегиального контроля, проводимый в НАТО и странах-партнерах на добровольной основе; к вопросам, исследуемым в процессе через Анкету для самооценки, можно получить доступ на https://www.nato.int/cps/en/natohq/topics_118004.htm. 
плинах и секторах. Тем не менее, устойчивость - один из тех терминов, который может пострадать от негибкого понимания его концептуальных параметров и практического значения. Анализ рисков и уязвимостей с усилением акцента на причинно-следственных связях оправдан в контексте дискуссий о том, как повысить устойчивость к внешним воздействиям. Работа НАТО по созданию эффективных и действенных оборонных институтов и по минимизации риска коррупции в сфере обороны и связанным с ней сектором безопасности за счет укрепления институциональной устойчивости и организационного духа добропорядочности, прозрачности и подотчетности может расширить охват дискуссии об устойчивости.

\section{Отказ от ответственности}

Выраженные здесь взгляды являются исключительно взглядами автора и не отражают точку зрения Консорциума оборонных академий и институтов изучения безопасности ПрМ, участвующих организаций или редакторов Консорциума.

\section{Благодарность}

Журнал Connections: The Quarterly Journal, Vol. 19, 2020 издается при поддержке правительства США.

\section{Об авторе}

Д-р Надя Миланова имеет обширный опыт в международных делах, вопросах безопасности, публичной дипломатии, оборонной политики и оборонных реформ в национальном и многостороннем контексте. С 2014 года д-р Миланова работала в качестве сотрудника по вопросам повышения добропорядочности (ВI) в штаб-квартире НАТО, где она вносит свой вклад в предоставление стратегических рекомендаций и наращивание потенциала в отношении борьбы с коррупцией и надлежащего управления в сфере обороны и связанным с обороной сектором безопасности. Она начала работать в НАТО в 2006 году в составе Отдела общественной дипломатии, а до этого работала в Организации по безопасности и сотрудничеству в Европе (ОБСЕ) в качестве главы ее Пражского офиса. На национальном уровне д-р Миланова работала дипломатом в Министерстве иностранных дел и руководила отделом двустороннего и регионального сотрудничества в Министерстве обороны Болгарии. Она также имеет опыт работы в области прав человека, занимаясь адвокатской деятельностью в ООН и ЕС. Она имеет докторскую степень в области политики Университета Эксетера, Соединенное Королевство, степень магистра международных отношений Школы права и дипломатии Флетчера при Университете Тафтса, США, и степень магистра английского языка и литературы Софийского университета, Болгария.

E-mail: nadia.milanova86@gmail.com 